(i-COME'20)

INTERNATIONAL CONFERENCE ON COMMUNICATION AND MEDIA 2020

\title{
MANAGERIAL PERSPECTIVE ON INTERNAL CRISIS COMMUNICATION (ICC)
}

\author{
Aida Suhana Abdul Hamid (a)*, Aida Zuliyana Ahmad Anuar (b), \\ Nan Zakiah Megat Ibrahim (c) \\ *Corresponding author
}

(a) Kolej University Poly-Tech MARA, Kuala Lumpur, Malaysia, aida_suhana@kuptm.edu.my

(b) Kolej University Poly-Tech MARA, Kuala Lumpur, Malaysia, aida_z@kuptm.edu.my

(c) Kolej University Poly-Tech MARA, Kuala Lumpur, Malaysia, zakiah@kuptm.edu.my

\begin{abstract}
Internal crisis communication (ICC) is an area of study that focuses on how the employees communicate inside the organization, among each other or management, or across organizational boundaries towards any negative event that happened. The immediate organizational reaction towards crisis involved a quality communication process that leads to trust and allowing communication activities among the stakeholders. In the previous study, the underpinning variables on ICC research are focused on social media usage, leadership, crisis responsibilities, error management culture, commitment, and perceived organizational support. The focus of the study even specifically on a certain aspect of ICC. Even more, the literature search provides a very common study from the employee perspective and a very limited study found in discussing the same area from the perspective of managerial. The interest of the study from a different perspective provides a different view in understanding the concept of ICC. The Situational Crisis Communication Theory (SCCT) used to explain the relationship involved in the study. Therefore, this conceptual study aims to develop a new model of ICC from the managerial perspective. The findings of this study identify two antecedents of ICC, namely leadership, and narrative communication. In addition, the study highlights a potential positive relationship between ICC and trust. An integrative conceptual framework and detailed summary table are presented in the paper.
\end{abstract}

2357-1330 @ 2021 Published by European Publisher.

Keywords: Internal crisis communication (ICC), leadership, narrative communication, Situational Crisis Communication Theory (SCCT), trust 


\section{Introduction}

Dealing and handling crisis communication can be considered as one of the most critical decision made by the organization. The impact of crisis being classified as a threat that damage organization reputation and effects the interactions of stakeholders (Coombs, 2007). Recent study on crisis communication area focusing on interrelationships between crisis events, communication strategies, and crisis perceptions (Adamu \& Mohamad, 2019). These three elements are crucial to gain further understanding on their relationship with organization crisis respond. External dimension of crisis communication highlighted in previous study includes how organizations protected their reputation during crisis (Adamu et al., 2016). Hence for internal dimension of crisis communication has long been ignored in the field of crisis communication research (Adamu et al., 2016).

A new challenge faced by the organization increase the interest in the internal crisis communication area and it opened a new finding on the development of a valid measurement scale to assessing ICC. The current trend of crisis communication studies primarily focusing on proactively organizational tactics and strategies responds towards crisis during the period after the crisis occurred (Taylor, 2010). An internal crisis communication will have an impact on effective commitment and perceived organizational support (Adamu et al., 2016). Current study of internal crisis communication highlighted on how on social media usage, leadership, crisis responsibility, error management culture, commitment, and organizational support as an element in internal crisis communication as mention by Adamu (2019). Its focuses on how the employees communicate inside the organization, among each other or management, or across organizational boundaries towards any negative event that happened. The study on internal crisis communication are critical due to the importance of internal stakeholder towards organization performance. Adamu (2019) also strengthen the need of employees by classifying that group of internal stakeholders as an organization heart.

\subsection{Situational Crisis Communication Theory (SCCT)}

Protecting an organizational reputation during the crisis can be implemented through the applications of Situational Crisis Communication Theory (SCCT). SCCT offers a framework for understanding and a mechanism for anticipating how stakeholders will react to a crisis in terms of the reputational threat posed by the crisis (Coombs, 2007) and provide theoretical underpinnings to support the relationship between antecedents (social media usage and crisis responsibility) with consequences (affective commitment and perceived organizational support) and internal crisis communication (Adamu, 2019).

\subsection{Leadership}

Leadership plays an important role in crisis management specifically in planning and managing crises (Tafra-Vlahović, 2013). In fact, Hollander (2013) mention that leadership has traditionally approached as a matter of leader qualifies and behaviors. The construction of leadership being the highlight to be complex and exposed to different interpretation (Bolden, 2004) when a few researchers 
have reported organizational leadership research has given attention on the internal aspects of a leader which comprise of physical traits and personality; while the other line of research has focused on the connection between leaders and their followers (Hughers et al., 2006).

\subsection{Narrative Communication}

Narratives are a common mode of communication (Fisher, 1987). Naturally, narrative communication involves the use of any of these types of stories to convey a point to another party or to receive information from another party (Hinyard \& Kreuter, 2007). Narratives also work as frames of explanation for (chains of) events and thus form a part of the process of sensemaking for employees where's its constructed identity (who we are) explains what happens (what we do), and this becomes particularly salient in times of transition and crisis when "abnormal" events need explaining (Strandberg \& Vigso, 2016). Some scholars mention about the existence of storytelling is narrative communication. As Strandberg \& Vigso (2016) pointing out, storytelling played a role in management's attempt at solving the situation, but they seem to have ignored the fact that the employees already had some well-established narratives explaining how things were done within the unit and the administration at large, and how the relations were between management and employees, as well as between the different groups of employees.

\subsection{Trust}

Trust was found to play a greater role during times of stability than during times of high uncertainty (Hasel, 2013). Hence, Seabright et al. (1992) prove that trust is vital for individuals working together to create effective and it works as a lubricant for social and interpersonal interactions (Arrow, 1974). To explain the relationship between leadership and trust, Pearson \& Clair (1998) stressed out the importance of leadership in organizational crisis in the context of the rush to make important decisions and execute change presumes that leadership is critical in a crisis. The role of crisis leader as mention by Boin et al. (2013) being categorized into five key tasks: i)sensemaking to process information from environmental cues to promote a collective understanding of the crisis, ii)decision-making and facilitating effective coordination among various parties, iii)meaning-making to provide an interpretation of the situation and to bring authentic hope and confidence to stakeholders, iv)rendering accountability to satisfy legal and moral requirements and to restore trust in the organization, and v)facilitating reflection and learning from the crisis.

\section{Problem Statement}

New challenge faced by the organization increase the interest on internal crisis communication area and it opened a new finding on development of valid measurement scale to assessing ICC. Current trend of crisis communication studies primarily focusing on proactively organizational tactics and strategies responds towards crisis during the period after the crisis occurred (Taylor, 2010). In fact, Adamu and Mohamad (2019) stated the concept of internal crisis communication has recently been given attention, due to the fact that internal stakeholders are proven to be the heart of any organization. 
However, a very limited study found focusing on what happened inside the organization during crisis (Frandsen \& Johansen, 2012).

Adamu (2019) are investigating the antecedents (social media usage, leadership, crisis responsibility and error management) and consequences (effective commitment and perceived organizational support) on internal crisis communication which specifically from employee's perspective. Hence, Tafra-Vlahović (2013) also reported an important and potentially useful elements of "leadership control" as part of future crisis management. Recent study suggested leadership as an antecedent of internal crisis communication (Adamu, 2019). When the organization respond and handle a crisis its being classified as an outcome of internal processes, relations, sensemaking and sense giving processes and leadership (Heide, 2013). Since the role of leadership becoming another strong element of crisis management (Jaques, 2012), Adamu (2019) suggested a further study on internal crisis communication from managerial perspective.

In fact, Kim (2018) also mentioning that through understanding of ECBs for sensemaking and sense giving in crisis situation it expands the scope of theoretical efforts of previous strategic management research specifically focused on relationship and leadership. It strongly shows the need of crises communication theories from strategic management perspective which emphasize employees as a valuable asset to the organization. Therefore, this study will contribute a new perspective of internal crisis communication specifically from perspective of managerial.

The construction of Table 01 explain a finding of study in internal crisis communication area. Based on extensive literature reviews, the summarization of the study lead to the proposed construction of this study as shown in Figure 01.

Table 1. Proposed focal construct of Internal Crisis Communication (ICC) from the managerial perspective.

\begin{tabular}{|c|c|c|}
\hline Antecedents & Focal Construct & Consequences \\
\hline $\begin{array}{l}\text { Social media usage, leadership, } \\
\text { crisis responsibility and error } \\
\text { management culture (Adamu, } \\
\text { 2019) }\end{array}$ & & $\begin{array}{l}\text { Affective commitment, perceived } \\
\text { organizational support (Adamu, } \\
\text { 2019) }\end{array}$ \\
\hline Leadership (Sutherland, 2016) & & Trust (Sutherland, 2016) \\
\hline $\begin{array}{c}\text { Communication, narrative, culture } \\
\text { and sensemaking (Standberg \& } \\
\text { Vigso, 2016). }\end{array}$ & $\begin{array}{l}\text { Internal Crisis Communication } \\
\text { from the Managerial Perspective }\end{array}$ & $\begin{array}{c}\text { Ambiguity, commitment and trust, } \\
\text { experience (Strandberg \& Vigso, } \\
\text { 2016) }\end{array}$ \\
\hline
\end{tabular}




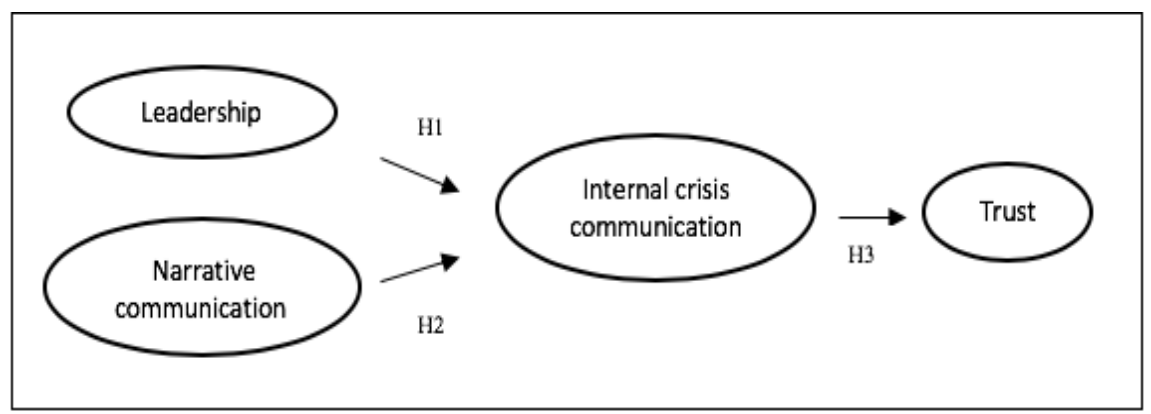

Figure 1. The proposed framework of ICC from the managerial perspective

\section{Research Questions}

- Is leadership a determinant of internal crisis communication?

- Is narrative communication a determinant of internal crisis communication?

- Does internal crisis communication have effect on trust?

\section{Purpose of the Study}

Aim of the study to examine the relationship of leadership and narrative communication with internal crisis communication, and the effect of internal crisis communication on trust.

\section{Research Methods}

This conceptual paper is carried out based on an extensive review of literature, articles, thesis, and books. The proposed research will use quantitative methods. The survey will be conducted by distributing a questionnaire to the respondents among Corporate Communication Managers from the public listed organization specifically in high-risk industry (oil and gas). In the first place, the data examination and screening will be conduct to get prepared for the following quantitative analysis, thereafter, the descriptive statistics will be present. Then a further reliability analysis will be conduct to attain an acceptable reliability threshold on each of the measurement scales. A confirmatory factor analysis will be conduct (CFA), to reassess the resulting solutions and in the theoretical model, the proposed relationship between the variables under investigation in this research will be assessed through applying structural equation modeling (SEM). Although, the measurement scales will be used in this study are largely adapted from the extensive literature and researcher are interested to construct a measurement scale for internal crisis communication from a managerial perspective.

\section{Findings}

The expected findings of the study will answer research questions and objectives.

\section{Conclusion}

From the extensive literature review done on internal crisis communication, leaderships and situational crisis communication theory, it was found that the importance of leadership role (managerial 
perspective) in internal crisis communication. As mention by Tafra-Vlahović (2013), leadership plays an important role in crisis management specifically in planning and managing the crisis. Hence, Hollander (2013) also mention that leadership has traditionally approached as a matter of leader qualifies and behaviours. Yet crises managers benefit from understanding how crisis communication can be used to protect reputational assets during a crisis (Coombs, 2007). However, a detailed study needs to be examined to clarify the result to give a positive contribution and extension to the internal crisis communication study from a managerial perspective. A conceptualization and construction of a suitable evaluation method are needed to prove the relationship. The results generated hopefully will provide significant analysis and new knowledge to other researchers or future studies in the internal crisis communication area focusing on managerial perspective.

\section{Acknowledgments}

The reported study was presented during i-COME' 2020 and supervised by i-COME' 2020 commitees. The study also funded by Internal Grant KUPTM Kuala Lumpur.

\section{References}

Adamu, A. A. (2019). A structural model of the antecedents and consequences of internal crisis communication [Doctoral thesis, Universiti Utara Malaysia].

Adamu, A. A., \& Mohamad, B. (2019). Developing a strategic model of internal crisis communication: Empirical evidence from Nigeria. International Journal of Strategic Communication, 13(2), $233-254$.

Adamu, A. A., Mohamad, B., \& Rahman, N. A. A. (2016). Antecedents of internal crisis communication and its consequences on employee performance. International Review of Management and Marketing, 6(S7), 33-41.

Arrow, K. J. (1974). The Limits of Organization. Norton.

Bolden, R. (2004). What is leadership? Centre for Leadership Studies, University of Exeter.

Boin, A., Kuipers, S., \& Overdijk, W. (2013). Leadership in times of crisis: A framework for assessment. International Review of Public Administration, 18(1), 79-91.

Coombs, W. T. (2007). Protecting organization reputations during a crisis: The Development and application of situational crisis communication theory. Corporate Reputation Review, 10(3), $163-176$.

Fisher, W. R. (1987). Human Communication as narration: Toward a philosophy of reason, value, and action. The University of South Carolina Press.

Frandsen, F., \& Johansen, W. (2012). The study of internal crisis communication: Towards an integrative framework. Corporate Communications: An International Journal, 16(4), 347-361.

Hasel, M. C. (2013). A question of context: The influence of trust on leadership effectiveness during crisis. Management, 16(3), 264-293.

Heide, M. (2013). Internal crisis Communication - the future of crisis management. Handbuch Krisenmanagement, Springer VS Wiesbaden, 195-209.

Hinyard, L. J., \& Kreuter, M. W. (2007). Using narrative communication as a tool for health behavior change: A conceptual, theoretical, and empirical overview. Health Education \& Behavior, 34(5), $777-792$.

Hollander, E. P. (2013). Inclusive leadership and idiosyncrasy credit in leader- follower relations. In M. G. Rumsey (Ed.), Oxford library of psychology: The Oxford handbook of leadership (122-143). Oxford University Press.

Hughers, L., Luthan, F., \& Norman, S. (2006). Authentic leadership: A new approach for a new time. In R. J. Burke, \& C. L. Cooper (Eds.), Inspiring leader. Routledge. 
Jaques, T. (2012). Crisis leadership: A view from the executive suite. Journal of Public Affairs, $366-372$.

Kim, Y. (2018). Enhancing employee communication behaviors for sensemaking and sensegiving in crisis situations: Strategic management approach for effective internal crisis communication. Journal of Communication Management, 22(4), 451-475.

Pearson, C. M., \& Clair, J. A. (1998). Reframing Crisis Management. Academy of Management Review, 23, 59-76.

Seabright, M. A., Leventhal, D. A., \& Fichman, M. (1992). Role of individual attachments in the dissolution of interorganizational relationships. Academy of Management Journal, 35(1), 122-160.

Strandberg, J. M., \& Vigso, O. (2016). Internal crisis communication an employee perspective on narrative, culture and sense making. Corporate Communication: An International Journal, 21(1), $89-102$.

Sutherland, I. E. (2016). Learning aand growing: trust, leadership, and response to crisis. Journal of Educational Administration, 55(1), 2 - 17.

Tafra-Vlahović, M. (2013). Leadership in crisis management. Recent Advances in Business Management and marketing, 85-90.

Taylor, M. (2010). Towards a holistic organizational approach to understanding crisis. In T. Coombs, \& S. J. Hollday, (Eds.). The Handbook of Crisis Communication (698-704). John Wiley and Sons, West Sussex. 